\title{
RENDIMENTO EM SUCO E RESÍDUOS DO MARACUJÁ EM FUNÇÃO DO TAMANHO DOS FRUTOS EM DIFERENTES PONTOS DE COLHEITA PARA O ARMAZENAMENTO
}

\author{
Antonione Araújo Coelho ${ }^{1}$, Sergio Agostinho Cenci ${ }^{2}$, Eder Dutra de Resende ${ }^{3 *}$ \\ RESUMO
}

Neste trabalho foi avaliada a influência do tamanho dos frutos em diferentes estádios de maturação durante a colheita do maracujá-amarelo sobre o rendimento em suco e a quantidade de resíduos, antes e após o armazenamento. Amostragens foram feitas numa lavoura comercial da região Norte Fluminense, RJ, no período de junho a agosto de 2007. Utilizou-se um teste estatístico segundo o método de amostragem simples ao acaso (ASA), considerando-se o nível de 5\% de significância. A amostra ideal foi dimensionada para uma população infinita de frutos tendo em vista além do nível de significância, o desvio de $10 \%$ em torno da média amostral. Foram determinados o ponto de colheita pela coloração da casca, o padrão de tamanho dos frutos, o rendimento em suco, a perda de massa na estocagem, a quantidade de resíduos e a espessura da casca. Verificou-se que houve influência do tamanho do fruto e do estádio de maturação no rendimento em suco e na espessura de casca do maracujá-amarelo, ocorrendo maior rendimento em suco e menor quantidade de casca nos frutos de maior padrão de tamanho. Os frutos colhidos com mais de $30,7 \%$ de área da casca amarelada apresentaram o máximo rendimento em suco e espessura mínima de casca.

Palavras-chave: Passiflora edulis, estádios de maturação, tamanho do fruto, espessura de casca, quantidade de resíduos

\section{YIELDS AND WASTES OF YELLOW PASSION FRUIT JUICE AS A RESULT OF FRUIT SIZE AND DIFFERENT STORAGE HARVESTING SPOTS}

\begin{abstract}
It is evaluated in this work the influence of fruit size at different ripening stages during the harvesting of yellow passion fruit for the production of juice and amount of waste before and after storage. Sampling was taken from a commercial orchard in the northern Fluminense region in the state of Rio de Janeiro, during the months June-August 2007. A statistical test was applied based on a simple random sampling method considering a level of significance of 5\%. The sample was dimensioned for an infinite population of fruit taking into account the level of significance and a deviation of $10 \%$ around the average data. It was determined the harvest point by the peel color, the standard size of the fruit, the juice yield, the amount of waste, the peel thickness and mass loss during storage. It was verified the influence of the ripening stages and fruit size on the juice yield, and the fruit peel thickness with higher juice yield and lower amount of peel for the fruit with higher standard size. Fruits harvested with at least $30.7 \%$ of yellow peel color presented the highest juice yield and the lowest peel thickness.
\end{abstract}

Keywords: Passiflora edulis, ripening stages, fruit size, peel thickness, amount of waste

\footnotetext{
Protocolo 103.046 de 11/11/2009

${ }^{1}$ Eng. Agrônomo, M.Sc. Produção Vegetal, Laboratório de Tecnologia de Alimentos/CCTA/Uenf, Avenida Alberto Lamego, 2000, Parque Califórnia, Campos dos Goytacazes-RJ, CEP: 28013-602, Fone: (22) 27397058, e-mail: aacoellho@ yahoo.com.br

${ }_{2}^{2}$ Pesquisador Dr., Laboratório de Fisiologia Pós-colheita, Embrapa Agroindústria de Alimentos, Av. das Américas, 29501, Guaratiba, Rio de Janeiro, CEP: 23020-470, Tel: (21)36229641, e-mail: cenci@ctaa.embrapa.br

${ }^{3}$ Professor Associado, Laboratório de Tecnologia de Alimentos, CCTA/UENF, e-mail: eresende@uenf.br (*autor para correspondência)
} 


\section{INTRODUÇÃO}

O maracujazeiro é uma frutífera botanicamente definida como planta trepadeira sublenhosa, da família Passifloracea e do gênero Passiflora, bastante cultivada e explorada de norte a sul do território brasileiro e de bom retorno econômico (Lima, 2002). O cultivo do maracujazeiro tem-se expandido no Brasil sendo, atualmente, o maior produtor mundial deste fruto. Segundo dados do IBGE (2009), a produção brasileira em 2007 chegou a 615.196 toneladas de frutos em uma área plantada de 44.363 hectares, com rendimento médio de $13.867 \mathrm{~kg} / \mathrm{ha}$.

$\mathrm{O}$ estádio mais adequado para a colheita do maracujá depende do destino dos frutos. A colheita dos frutos destinada ao consumo "in natura" pode ser feita quando os frutos ainda estiverem verdes na região próxima ao pedúnculo, devendo apresentar algumas características bem definidas, tais como: coloração uniforme, boa aparência, tamanho grande, proporcionando uma classificação comercial adequada ao padrão de mercado, resistência ao transporte e boa conservação póscolheita (Oliveira et al., 1994, citado por Nascimento, 1996).

A principal forma de comercialização do maracujá é como suco, sendo as cascas e as sementes, resultantes de seu processamento, os principais subprodutos (Oliveira, 1980). De acordo com Oliveira et al. (2002), os subprodutos correspondem a cerca de 65 a $70 \%$ do peso do fruto, que não é aproveitado normalmente, tornando-se um grande problema de resíduo agroindustrial. A parte aproveitável do maracujá para se fazer o suco é a polpa, que representa aproximadamente $33 \%$ do peso total do fruto. A casca, composta predominantemente de um tecido esponjoso e que é facilmente desidratada, ocupa quase $60 \%$ do peso do maracujá. Este subproduto tem sido pesquisado e se mostrado viável como fonte alimentar de bom valor nutricional, reduzindo custos e, ao mesmo tempo, diminuindo o passivo ambiental proveniente do processamento industrial (Bertipaglia et al., 2000).

As sementes representam cerca de 6 a $12 \%$ do peso total do fruto (Ferrari et al., 2004). Segundo Tocchini (1994), elas podem ser boas fontes de óleo, carboidratos, proteínas e minerais, apesar do alto conteúdo de celulose e lignina que podem limitar seu uso na alimentação animal, principalmente monogástricos. O óleo de sabor agradável e odor suave se compara ao óleo de algodão em valor nutritivo e digestibilidade.

A quantidade de resíduos do maracujá (casca e sementes) gerada por toneladas de suco processadas, é bastante elevada. Demandam-se soluções alternativas para o aproveitamento desses resíduos, o que somente será possível através do incentivo ao desenvolvimento de novas pesquisas (Duringa \&Yamanaka, 1987).

A espessura da casca é uma das características de grande importância para o maracujá-amarelo. De acordo com Manica (1981), a espessura da casca do maracujá varia de $0,63 \mathrm{~cm}$ a $0,71 \mathrm{~cm}$ mas pode apresentar valores maiores, dependendo de fatores climáticos e do tipo de solo, que provocam alterações fisiológicas na população, em busca de mecanismos para sobreviver em novo ambiente. Variações podem ocorrer dentro da mesma espécie, em um mesmo pomar e entre as diferentes regiões de cultivo, podendo-se aproveitar as qualidades desejáveis, por meio da seleção.

O maracujazeiro é uma planta de fecundação cruzada por excelência; apresenta elevada taxa de auto-incompatibilidade, também observada em $P$. alata (Vasconcellos et al., 2001). Isto resulta na perda de identidade genética e amplia a variabilidade dos pomares, ocorrendo grande variabilidade com relação ao tamanho dos frutos, coloração interna e externa e outras características do fruto, tamanho da planta, coloração de folhas, caule e gavinhas e suscetibilidade a patógenos (Oliveira, 1980). Os frutos do maracujazeiro amarelo têm a forma arredondada ou ovalada, com peso variando de 31,6 a 176,2g. O diâmetro varia de 4 a $9 \mathrm{~cm}$ e seu comprimento varia de 4,62 a $8,29 \mathrm{~cm}$ (Carvalho, 1974).

De acordo com Vianna-Silva et al. (2008), frutos com padrão de tamanho grande $(>200 \mathrm{~g})$ e de formato ovalado $(7,66 \mathrm{~cm}<$ diâmetro $<8,59 \mathrm{~cm}$ e $9,17 \mathrm{~cm}<$ comprimento $<$ $10,04 \mathrm{~cm})$ apresentam rendimento em suco de aproximadamente $40 \%$ quando colhidos com mais de $30 \%$ de área da casca amarelada.

O objetivo do presente trabalho foi avaliar o rendimento em suco e a quantidade de resíduos do maracujá-amarelo em função do tamanho dos frutos em diferentes pontos de colheita, antes e após o completo amadurecimento em câmara de armazenamento, visando à comercialização in natura ou ao o processo de industrialização. 


\section{MATERIAL E MÉTODOS}

Neste trabalho foram utilizados frutos de maracujá-amarelo (Passiflora edulis Sims), colhidos numa lavoura localizada no município de Campos dos Goytacazes, RJ. O sistema de polinização foi manual. A área plantada é de 1,38 ha possuindo declividade de 0 a $5 \%$ e o solo é do tipo areno-argiloso. O sistema de condução das plantas é do tipo espaldeira, com 1 fio. A distância entre linhas de plantio é de $3,5 \mathrm{~m}$, a distância entre plantas de $4 \mathrm{~m}$ e com densidade populacional de 833 plantas/ha. O sistema de irrigação é do tipo gotejamento com intervalo de 8 dias entre irrigações.

Os frutos foram colhidos entre os meses de Junho a Agosto de 2007, cujas características climáticas foram caracterizadas por uma precipitação média de $53 \pm 10 \mathrm{~mm}$ de chuva, temperatura média de $21 \pm 1,5{ }^{\circ} \mathrm{C}$ e umidade relativa de $80 \pm 5 \% \mathrm{UR}$.

Após a colheita os frutos foram transportados imediatamente para o laboratório, onde foram lavados e sanitizados com água clorada (100ppm de cloro ativo) e secados. Metade do lote de frutos compreendendo 20 maracujás-amarelos provenientes de cada estádio de maturação, foi caracterizada no dia da colheita. A outra metade foi estocada a $22^{\circ} \mathrm{C}$ e $90 \%$ UR, até o completo amarelecimento da casca quando então foram avaliados. Os frutos colhidos maduros serviram como parâmetro de referência.

Para a caracterização física em função do tamanho os maracujás foram selecionados em 5 lotes de diferentes padrões de tamanho, utilizando-se um paquímetro manual para a realização das medidas de comprimento longitudinal $(\mathrm{cm})$ e largura equatorial $(\mathrm{cm})$, sendo também padronizados no estádio totalmente maduro e com o mesmo formato ovalado, definido pela razão entre comprimento (C) e largura (L) do fruto (Razão C/L).

No momento da colheita os frutos foram selecionados em 7 diferentes estádios de maturação. A cor da casca foi caracterizada através de um Colorímetro Hunterlab MiniScan Spectrophotometer (MiniScan XE Plus), utilizando iluminante D65, ângulo de observação de $10^{\circ}$ no sistema $L, a$, b. As medidas foram realizadas em dois pontos equidistantes da face exposta e não-exposta do fruto ao Sol, compreendendo a região mediana da parte superior (pedúnculo) e inferior (base) dos frutos. A escala de cor foi obtida conforme
Silva et al. (2008), utilizando-se os valores médios do parâmetro de Hunter b e se calculando a diferença entre as determinações médias da cor em cada estádio de maturação e o estádio verde inicial, dividida pela variação total do parâmetro de Hunter b entre os estádios verde e totalmente maduro.

Foram avaliadas as características de rendimento em suco $(\%)$, quantidade de casca (\%) e quantidade do resíduo (sementes com arilo,\%), espessura de casca $(\mathrm{cm})$ em quatro pontos equidistantes da região equatorial do fruto e massa dos frutos (g). Após o corte, a extração e a pesagem da polpa bruta em balança analítica (Gehaka, AG 200), o material contido no Becker foi processado com um homogeneizador (marca Britânia) no módulo pulsar, para separar as sementes e o arilo; em seguida prensado (prensa manual) com auxílio de tela filó $(1 \mathrm{~mm})$ previamente pesada, conforme descrito por Silva et al. (2008). O peso do resíduo com o filó foi avaliado em balança analítica (Gehaka, AG 2000), sendo a quantidade de suco obtida pela diferença de massa em relação à polpa bruta e padronizada para $100 \mathrm{~g}$ do fruto. Tal procedimento foi adotado para minimizar os erros relativos ao material retido nos utensílios de extração. $\mathrm{O}$ percentual de casca foi obtido pela diferença entre a massa total do fruto e o peso da polpa bruta dividido pela massa total e padronizado para $100 \mathrm{~g}$.

Utilizou-se um teste estatístico segundo o método de amostragem simples ao acaso (ASA), com $5 \%$ de significância e se considerando uma população infinita de maracujás-amarelos. As médias foram comparadas através do Teste 't', para o intervalo de confiança. A amostra ideal foi dimensionada para população infinita de frutos considerando-se, além do nível de significância o desvio de $10 \%$ em torno da média amostral, para todas as características analisadas.

\section{RESULTADOS E DISCUSSÃO}

Tanto na caracterização de tamanho dos frutos como na caracterização do estádio de maturação, a amostragem de 20 frutos foi representativa de uma população infinita de maracujás. Os diversos padrões de tamanho estão indicados na Tabela 1 , na qual se observa a homogeneidade de formato oval do fruto, indicada pela Razão C/L. 
Tabela 1 - Medidas de massa, comprimento (C), largura (L) e razão C/L dos frutos de maracujáamarelo colhidos em 5 lotes de diferentes padrões de tamanho

\begin{tabular}{ccccc}
\hline $\begin{array}{c}\text { PADRÕES DE } \\
\text { TAMANHO }\end{array}$ & $\begin{array}{c}\text { MASSA } \\
\left(\mathbf{g}^{*}\right)\end{array}$ & $\begin{array}{c}\text { COMPRIMENTO } \\
(\mathbf{c m})\end{array}$ & $\begin{array}{c}\text { LARGURA } \\
(\mathbf{c m})\end{array}$ & $\begin{array}{c}\text { RAZÃO C/L } \\
\left(\mathbf{c m}^{*}\right)\end{array}$ \\
\hline 1 & $251,54( \pm 14,97)$ & 11,0 & 8,6 & $1,28( \pm 0,03)$ \\
2 & $237,35( \pm 15,09)$ & 10,9 & 8,2 & $1,33( \pm 0,04)$ \\
3 & $144,62( \pm 11,56)$ & 9,7 & 7,3 & $1,32( \pm 0,04)$ \\
4 & $123,26( \pm 5,89)$ & 9,0 & 6,6 & $1,36( \pm 0,04)$ \\
5 & $77,54( \pm 5,73)$ & 7,0 & 5,9 & $1,20( \pm 0,04)$ \\
\hline
\end{tabular}

( ${ }^{*}$ Médias caracterizadas pelo intervalo de confiança a nível de 5\% de significância)

Para a caracterização física em função do tamanho do fruto a análise estatística mostrou que os frutos maiores, com padrão de tamanho 1 e 2 , apresentaram maior rendimento em suco (média de 35\%) que os frutos menores (tamanhos 3, 4, 5). Nota-se tendência de redução de rendimento em suco entre os tamanhos 3, 4 e 5, mas não se identificaram diferenças significativas entre eles (Figura 1). Os frutos de padrão 1 e 2 são classificados Extra 3A, conforme descrito por Nascimento et al. (1999). Os frutos do padrão de tamanho 3 possuem média de $144 \mathrm{~g}$, sendo classificados como Extra A, dando um rendimento médio de $22 \%$. O padrão de tamanho 4 representa frutos com $123 \mathrm{~g}$ e são classificados como Extra, dando rendimento médio de 20\%; já o padrão de tamanho 5 representa frutos com $77 \mathrm{~g}$ e são classificados como Especiais, mas têm baixo rendimento, ou seja, $18 \%$ em suco. Segundo Haendler (1965), os maracujás utilizados no processamento industrial devem apresentar rendimento em suco superior a $33 \%$.

Os frutos maiores, com padrão de tamanho 1 e 2, tiveram menor porcentagem de casca (média de 53\% da massa total do fruto) que os frutos menores (tamanhos $3,4,5$ ), isto é, sua média foi de $67 \%$ de casca; porém, não se identificaram diferenças significativas entre eles.

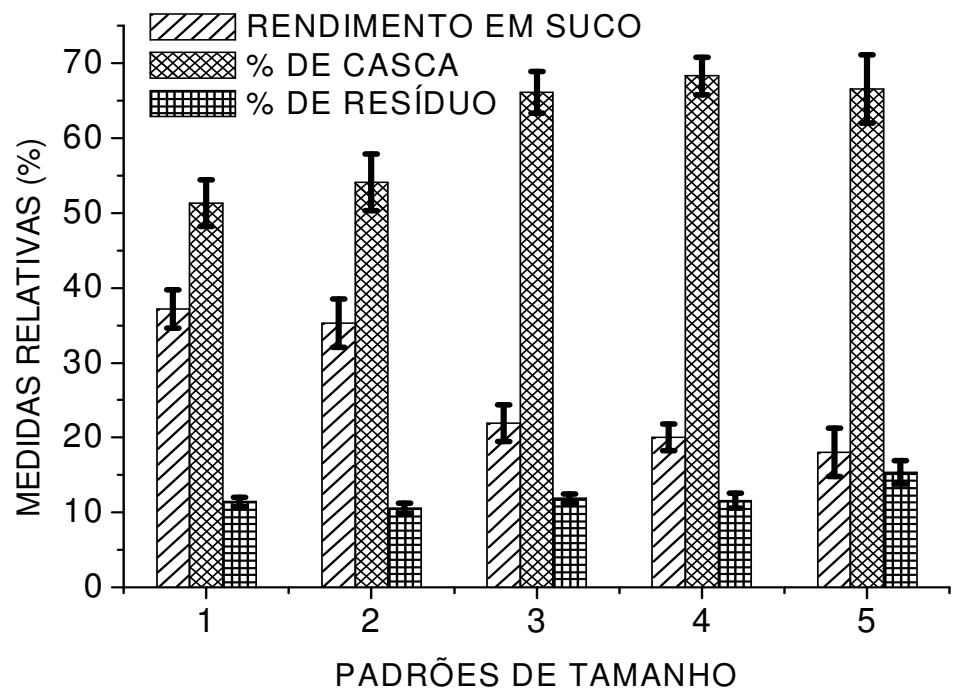

As barras verticais representam os intervalos de confiança a $p \leq 0,05$

Figura 1 - Valores médios de rendimento em suco, \% de casca e \% de sementes com arilo em função do tamanho dos maracujás-amarelos.

Nota-se também na Figura 1, que ocorreu um rendimento menor em suco, nos padrões de tamanho 3, 4 e 5. Essas menores magnitudes de rendimento em suco nesses padrões de tamanho podem ser atribuídas ao maior percentual de casca encontrado nos mesmos. 
Utilizando-se os maiores padrões de tamanho como referência para cada tonelada de frutos processada pela indústria ou consumida "in natura" obtem-se aproximadamente $530 \mathrm{~kg}$ de casca. Segundo dados do IBGE (2009), a produção de frutos de maracujá-amarelo gira, aproximadamente em torno de 615 mil toneladas e desta forma se estima que a quantidade mínima de casca seja de 325,9 mil toneladas por ano.

Nota-se, na Figura 1, que os padrões de tamanho 1, 2, 3 e 4 apresentaram menores magnitudes de sementes com arilo, em torno de $11.5 \%$ não apresentando diferença significativa entre eles, sendo que somente no padrão de tamanho 5 é que ocorreu maior magnitude de quantidade de resíduo, em torno de $15 \%$, diferindo dos demais tamanhos.

A variação linear do parâmetro de Hunter b permitiu a determinação da escala de maturação dos frutos nos diferentes pontos de colheita. A escala de cor determinada através do parâmetro de Hunter b apresentou o estádio 1 com $0 \%$, estádio 2 com $5,1 \%$, estádio $3 \mathrm{com}$ $30,7 \%$, estádio 4 com $40,3 \%$, estádio 5 com $66,1 \%$, estádio 6 com $74,7 \%$ e estádio 7 com $98,4 \%$ de coloração amarela.

A padronização da cor nos diferentes pontos de colheita do maracujá-amarelo está indicada nas Figuras 2.a, 2.b, 2.c, respectivamente, para as médias dos parâmetros de Hunter L, b, a. Verifica-se que a evolução da luminosidade da casca (Hunter L) e o desenvolvimento da cor amarela (Hunter b) ocorrem de forma progressiva e linear com o processo de amadurecimento mas a transformação da clorofila indicada pela perda da cor verde da casca (Hunter a) ocorre de forma exponencial.

Para a caracterização do ponto de colheita para o armazenamento, os maracujásamarelos analisados nos estádios 1 e 2 apresentaram maiores magnitudes de perda de massa $(10,2 \%$ e $7,5 \%$ respectivamente), não ocorrendo diferença estatística entre eles (Figura 3). Esta maior perda de massa está relacionada com o maior tempo de amadurecimento dos frutos, alcançando 31 e 22 dias, respectivamente.

Na Figura 3 os valores de tempo indicam o período mínimo (dias de armazenamento) para atingir o completo amarelecimento da casca
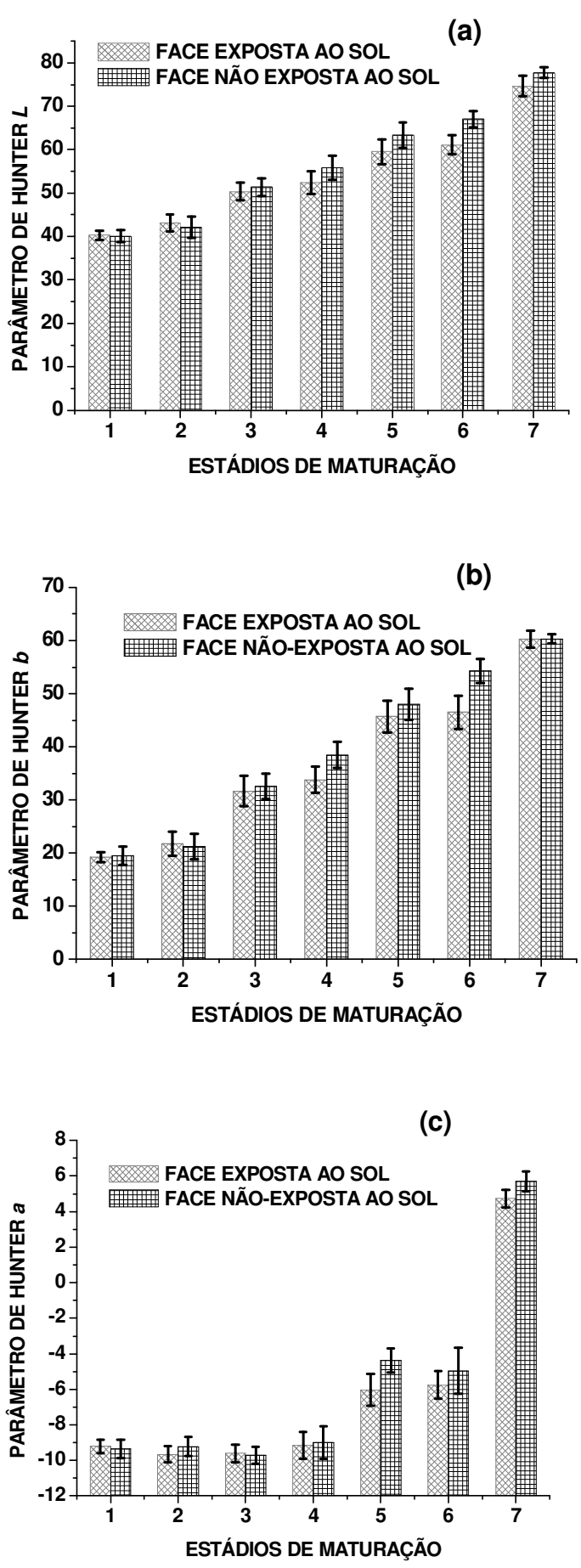

As barras verticais representam os intervalos de confiança em nível de $0,05 \%$

Figura 2 - Valores médios dos parâmetros de Hunter L (2.a), Hunter b (2.b) e Hunter a (2.c) das faces exposta e não-exposta da casca do fruto de maracujá-amarelo ao sol, colhidos em 7 diferentes estádios de maturação. 


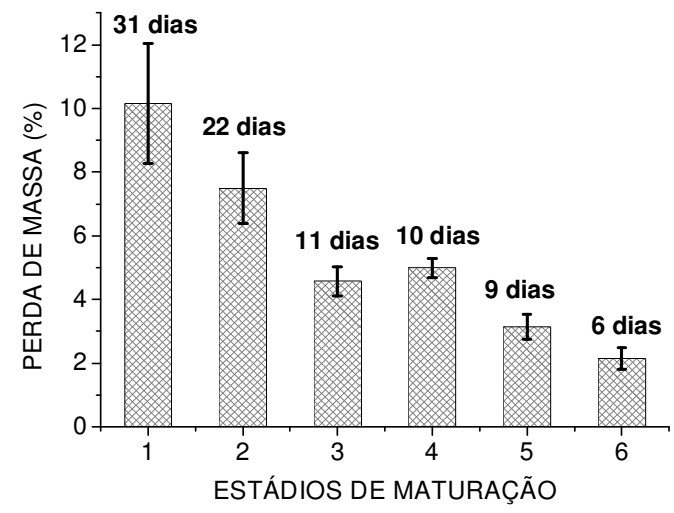

As barras verticais representam os intervalos de confiança a nível de $0,05 \%$

Figura 3 - Valores médios de perda de massa em função dos estádios de maturação do maracujá-amarelo..

No caso dos frutos estocados a partir do estádio de maturação 3 (30,7\% de cor amarela), verifica-se que a perda de massa foi de $4,6 \%$ para um tempo de amadurecimento de 11 dias, ao passo que os frutos do estádio $6 \quad(74,7 \%$ de cor amarela) apresentaram $2,1 \%$ de perda de massa dentro de 6 dias necessários para o completo amadurecimento. Nessas condições não ocorreram sintomas de murchamento nem de enrugamento da casca, indicando a boa qualidade dos frutos colhidos com no mínimo $30,7 \%$ de área da superfície da casca amarelada. No estudo com maracujá-roxo os frutos estocados a $25^{\circ} \mathrm{C}$ atingiram valores de perda de massa da ordem de $35 \%$ durante 30 dias de armazenamento (Shiomi et al., 1996). A perda de matéria fresca que ocorre durante $o$ armazenamento do maracujá-amarelo é fator limitante para sua conservação. Gama et al. (1991) observaram que aos 28 dias de armazenamento do maracujá-amarelo sob $6^{\circ} \mathrm{C}$, os frutos apresentaram $9,29 \%$ de perda de matéria fresca.

A razão $\mathrm{C} / \mathrm{L}$ obteve, em todos os estádios de maturação dos maracujás, valor maior que 1 , significando que todos os frutos apresentaram formato ovalado, ou seja comprimento maior que a largura (Figura 4).

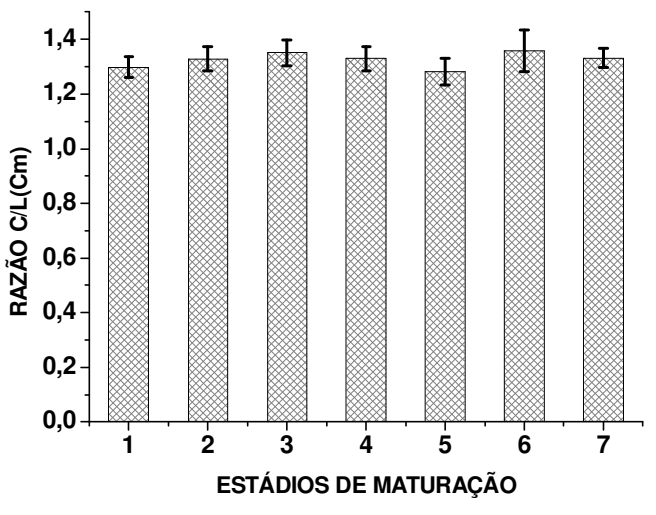

As barras verticais representam os intervalos de confiança a nível de $0,05 \%$

Figura 4 - Valores médios de Razão C/L em função dos estádios de maturação do maracujáamarelo.

Verifica-se, na Figura 4, que os frutos foram adequadamente selecionados para que $\mathrm{SE}$ obtivesse uma padronização de tamanho e de formato dos maracujás-amarelos, necessária para avaliar o rendimento em suco e de resíduos dos frutos nos diferentes estádios de maturação. O formato oval dos frutos foi selecionado por serem mais comerciais e apresentarem maior rendimento em suco (Manica,1981). De acordo com Akamine et al. (1956), citados por Nascimento (1996), frutos com o formato oval superam em até $10 \%$ o rendimento em suco dos frutos de formato redondo. Os valores de comprimento e a largura dos frutos apresentaram média de $10,75 \mathrm{~cm}$ e $8,22 \mathrm{~cm}$, respectivamente. Resultados similares foram encontrados por Vianna-Silva et al. (2008) que verificaram, para o maracujá amarelo, variação de comprimento longitudinal entre $9,9 \mathrm{~cm}$ e $9,1 \mathrm{~cm}$ e para diâmetro equatorial variando entre $7,7 \mathrm{~cm}$ e $8,1 \mathrm{~cm}$.

Os frutos colhidos mais verdes nos estádios 1 e 2 apresentaram maior espessura de casca que os frutos dos estádios mais maduros, conforme observado também por Vianna-Silva et al. (2008). A partir do estádio 3 (30,7\% de cor amarela) não ocorreu variação das medidas de espessura de casca. Os frutos do estádio verde apresentaram valores de espessura de casca de $0,86 \mathrm{~cm}$, ao passo que os frutos colhidos a partir do estádio 3 apresentaram valor médio de $0,52 \mathrm{~cm}$ (Figura 5).

A expressiva redução de espessura de casca ao longo do armazenamento dos frutos 
colhidos nos estádios 1 e 2 pode ter sido influenciada pela perda de massa ocorrida ao longo da estocagem (Figura 3). Segundo Oliveira et al. (1988), a maior espessura de casca está relacionada ao menor rendimento em suco. Desta forma, tanto a indústria como o mercado de frutos in natura consideram a espessura de casca primordial.

Os estádios 1 e 2 apresentaram média menor de rendimento em suco, $21,2 \%$ e $25,5 \%$, respectivamente, o que pode ser atribuído ao fato de, nesses estágios, os frutos não terem atingido a maturidade fisiológica; além disso, os frutos não atingiram o seu completo amarelecimento, apresentando murchamento e necroses de podridões ao final da estocagem. Os frutos colhidos nos estádios 1 e 2, apresentaram maior espessura de casca (Figura 5) e menor rendimento em suco (Figura 6). A partir do estádio 3 (30,7\% de cor amarela), observa-se que os frutos atingiram as maiores médias dos valores de rendimento em suco, $39,2 \%$, ao final da estocagem. Haendler (1965), afirmou que o rendimento em suco considerado para a industrialização é de no mínimo $33 \%$ da massa total do fruto. Desta forma, pode-se verificar que a partir do terceiro estádio os frutos atingiram o valor mínimo necessário de rendimento em suco, exigido pela indústria. Ressalta-se, entretanto, que os padrões de frutos grandes utilizados neste experimento influenciaram no alto rendimento em suco.

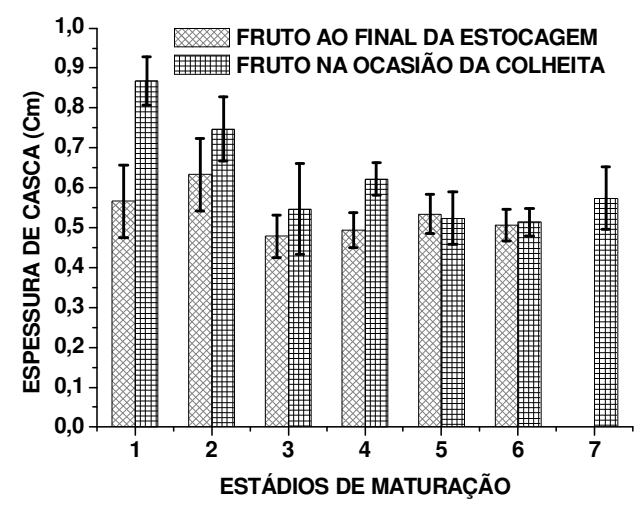

As barras verticais representam os intervalos de confiança a nível de $0,05 \%$.

Figura 5 - Médias de espessura de casca em função dos estádios de maturação do maracujáamarelo.

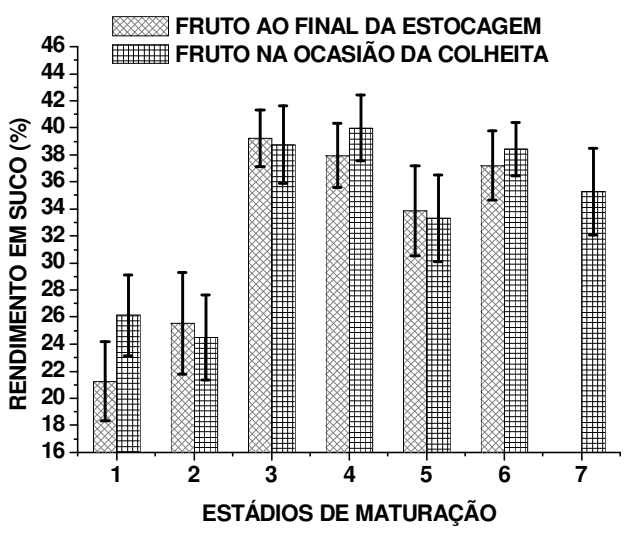

Barras verticais representam os intervalos de confiança a nível de $0,05 \%$

Figura 6 - Médias de rendimento em suco, em função dos estádios de maturação do maracujáamarelo.

De acordo com o trabalho de ViannaSilva et al. (2008), os maracujás-amarelos de grande padrão de tamanho, colhidos nos meses de maio a setembro (safra de inverno), apresentaram as mesmas magnitudes de valores de rendimento em suco alcançado no presente trabalho, atingindo os valores máximos no estádio de maturação, em que os frutos apresentavam $21,3 \%$ de área da superfície da casca amarelada.

\section{CONCLUSÕES}

O padrão de tamanho do fruto e o estádio de maturação influenciaram no rendimento em suco e na quantidade de casca do maracujáamarelo, ocorrendo maior rendimento em suco e menor proporção de casca nos frutos de maior padrão de tamanho.

A homogeneização de formato e a identificação do padrão de tamanho dos frutos foram validadas através da razão $\mathrm{C} / \mathrm{L}$, garantindo uma análise precisa de rendimento em suco e proporção de casca, sementes e arilo.

Os frutos maiores, com padrão de tamanho 1 e 2, apresentaram menor porcentagem de casca (média de $53 \%$ da massa total do fruto) que os frutos menores (Tamanhos 3, 4, 5), esses com média de $67 \%$ de casca.

A quantidade de sementes com arilo não foi influenciada pelo padrão de tamanho dos frutos, sendo que os frutos grandes, com média de 251,54 g, e menores, com 123,26 g, 
mostraram a mesma quantidade de resíduo, em torno de $11,5 \%$.

Os frutos colhidos com mais de $30,7 \%$ de área da casca amarelada apresentaram o máximo rendimento em suco e espessura mínima de casca.

\section{AGRADECIMENTOS}

Ao $\mathrm{CNPq}$, pelo apoio financeiro ao projeto CTAGRO/Edital MCT/CNPq $\mathrm{n}^{\circ}$ 04/2006 Processo $n^{\circ}$ 554408/2006-6; ao Sr. Jaime Viana, pela matéria-prima e à CAPES, pela bolsa de pesquisa.

\section{REFERÊNCIAS BIBLIOGRÁFICAS}

Bertipaglia, L. M. A., Alcade, C. R., Siqueira, G. B., Melo, G. M. P., Andrade, P. Degradação in situs da matéria seca, proteína bruta e fibra em detergente neutro de silagens de milho e resíduo da extração do suco de maracujá. Acta Scientiarum, Maringá, v. 22, n. 3, p. 765-769, 2002.

Carvalho, A. M. Melhoramento cultural do maracujazeiro. In: simpósio da cultura do maracujá, 1., 1974, Campinas. Anais. Campinas: CATI, p.8-10, 1974.

Duringa, J. F., Yamanaka, L. H. Aproveitamento de subprodutos da fabricação de suco de maracujá, in: Ruggiero, C. Cultura do maracujazeiro. Ribeirão Preto, Legis summa, 1987, p. 202-209.

Ferrari, R. A., Colussi, F., Ayub, R. A. Caracterização de Subprodutos da Industrialização do Maracujá: Aproveitamento das Sementes. Revista Brasileira de Fruticultura, Jaboticabal SP, v. 26, n. 1, p. 101-102, 2004.

Gama, F. S. N., Manica, I., Kist, H. G. K., Accorsi, M. R. Aditivos e embalagens de polietileno na conservação do maracujá amarelo armazenado em condições de refrigeração. Pesquisa Agropecuária Brasileira, Brasília, v.26, n.3, p.305- 10, 1991.

Haendler, L. La passiflora: Composition chimique et ses possibilités de transformation. Fruits, Paris, v. 20, n. 5, p. 235-245, 1965.

IBGE - Instituto Brasileiro de Geografia e Estatística, 2007. Disponível em $<$ http://www.sidra.ibge.gov.br/bda/agric/def ault.asp? $\mathrm{z}=\mathrm{t} \& \mathrm{o}=10 \& \mathrm{i}=\mathrm{P}>$ Acesso $\quad \mathrm{em}$ : Fevereiro de 2009.

Lima, A. A. Maracujá produção: aspectos técnicos. Cruz das Almas: Embrapa Mandioca e Fruticultura, Cruz das Almas. Brasília: Embrapa Informação Tecnológica, (Frutas do Brasil), 15, p. 103, 2002.

Manica, I. Fruticultura tropical. Maracujá, São Paulo, SP. Ceres, p.19-32, 1981.

Nascimento, T. B., Ramos, J. D., Menezes, J. B. Características físicas do maracujá amarelo produzido em diferentes épocas. Pesquisa Agropecuária Brasileira, v. 34, n.12, p. 2353-2358, 1999.

Nascimento, T. B. Qualidade do maracujá amarelo produzido em diferentes épocas no sul de Minas Gerais. Lavras. MG, 1996, 56p. Dissertação (Mestrado). Universidade Federal de Lavras, UFLA.

Oliveira, L. F., Nascimento, M. R. F., Borges, S. V., Ribeiro, P. C. N., Ruback, V. R.. Aproveitamento alternativo da casca do maracujá amarelo (Passiflora edulis f. flavicarpa Deg.) para produção de doce em calda. Ciência e Tecnologia de Alimentos, v. 22, n. 3, p. 259-262, 2002.

Oliveira, J. C., Ferreira, F. R., Ruggiero, C., Nakamura, L. Caracterização e avaliação de germoplasma de Passiflora edulis. In: congresso brasileiro de fruticultura, Campinas. Anais. Sociedade Brasileira de Fruticultura, v. 2, p. 585-590, 1988.

Oliveira, J. C. Melhoramento genético de Passiflora edulis $f$. flavicarpa Deg. visando aumento de produtividade. Jaboticabal: FCAVJ: UNESP, 35p., 1980.

Silva, T. V., Resende, E. D., Viana, A. P., Pereira, S. M. F., Carlos, L. A., Vitorazi, L. Determinação da escala de coloração da casca e do rendimento em suco do maracujá-amarelo em diferentes épocas de colheita. Revista Brasileira de Fruticultura, v. 30, p. 880-884, 2008.

Shiomi, S., Wamocho, L. S., Agong, S. G. Ripening characteristics of purple passion fruit on and off the vine. Postharvest Biology and Technology, v.7, p. 161-170, 1996.

Tocchini, R. P. III Processamento: produtos, caracterização e utilização. In: Maracujá: cultura, matéria-prima e aspectos econômicos. 2. ed. Campinas: ITAL, 1994. Revista e ampliada, p. 161-175.

Vasconcellos, M. A. S., Brandão Filho, J. U. T., Vieites, R. L. Maracujá-doce. In: 
BRÜCKNER, C. H.; PICANÇO, M.C. Maracujá: tecnologia de produção, póscolheita, agroindústria e mercado. Porto Alegre: Cinco Continentes, 472p, 2001.

Vianna-Silva, T., Resende, E. D., Pereira, S. M.
A., Vitorazi, L. Influência dos estádios de maturação sobre as características físicas dos frutos de maracujá-amarelo. Bragantia, v. 67, n. 2 , p. $267-273,2008$. 
Revista Brasileira de
Produtos Agroindustriais Brazilian Journal of Agro-industrial Products 